\title{
Sustentabilidade do licenciamento ambiental minerário em Minas Gerais: caso aplicado
}

\author{
Sustainability of the mineral environmental licensing in Minas Gerais: case applied
}

Paula Fernandes dos Santos ${ }^{1 *} \oplus$, Luís Antônio Coimbra Borges'

口

\begin{abstract}
RESUMO
A avaliação de impactos ambientais, introduzida por meio da Política Nacional de Meio Ambiente (PNMA), ganhou espaço primordialmente dentro do licenciamento ambiental, cujo modelo atual é questionado pela sua ineficácia em compensar ao ambiente a perda dos recursos naturais. Este estudo teve como objetivo analisar de forma técnica e legal o licenciamento ambiental minerário na Região do Alto São Francisco, Minas Gerais, por intermédio do histórico e fluxo atual dos processos, do levantamento de dados dos de Estudos de Impacto Ambiental, do cumprimento dos Termos de Referência e da legislação ambiental, analisando estes dados pelo método Analytic Hierarchy Process (AHP). Os resultados demonstraram que o licenciamento ambiental não cumpre a função de compensar os impactos socioambientais causados pela atividade nem os requisitos legais obrigatórios ao processo.
\end{abstract}

Palavras-chave: licenciamento ambiental; estudo de impacto ambiental; termo de referência.

\begin{abstract}
The assessment of environmental impacts, introduced by the National Environmental Policy, has earned a place within the environmental licensing process, which is currently questioned due to its ineffectiveness to compensate nature for resources' loss. This study aimed at technically and legally assessing the mineral environmental licensing process in the Region of Alto São Francisco, Minas Gerais, through history and current flow of processes, as well as by surveying data from Studies on Environmental Impact, and compliance with the Terms of Reference and applicable environmental law, using the Analytic Hierarchy Process (AHP). The results showed that the environmental licensing process does not meet the needs for compensating the socioenvironmental impacts caused by activity and does not comply with the legal requirements that are mandatory in the process.
\end{abstract}

Keywords: environmental licensing; study on environmental impact; term of reference.

\section{INTRODUÇÃO}

Desenvolvimento sustentável é aquele que procura satisfazer as necessidades da geração atual, sem comprometer a capacidade das gerações futuras de satisfazerem as suas próprias necessidades (RELATÓRIO DE BRUNDTLAND, 1987). Após a publicação da National Environmental Policy Act (NEPA), nos Estados Unidos, quando a avaliação de impactos foi instituída legalmente pela primeira vez, ela foi organizada gradativamente no mundo todo. Dois anos após a NEPA entrar em vigor, em 1972, foi realizada a Conferência de Estocolmo, que debateu amplamente o conceito de meio ambiente e introduziu, no cenário mundial, a ideia de sustentabilidade política, econômica e ecológica, que propunha o desenvolvimento ecologicamente prudente, economicamente viável e socialmente justo (CABRAL, 2006; RONZA, 1998).

No Brasil, merecem destaque, como ato legislativo, a promulgação da Lei Federal nº 6.938/81 (BRASIL, 1981), que instituiu a Política Nacional do Meio Ambiente (PNMA), e a Constituição Federal de 1988 (CF/88), que elevou o meio ambiente ao status de direito constitucional e como parte das manifestações e dos encontros sociais, a realização da Rio 92, conferência das Nações Unidades para o Meio Ambiente e Desenvolvimento, que deu visibilidade ao país e às questões ambientais. A PNMA instituiu como um de seus instrumentos a avaliação de impactos ambientais, além de outros igualmente importantes, como o licenciamento ambiental, o estabelecimento de padrões de qualidade ambiental, entre outros.

A avaliação de impactos em Minas Gerais também teve início na década de 1980, seguindo a tendência nacional, com a promulgação da Lei Estadual no $7.772 / 80$, que dispõe sobre a proteção, melhoria e conservação do meio ambiente (MINAS GERAIS, 1980), e se consolidou com a criação da Secretária de Estado de Meio Ambiente e Desenvolvimento Sustentável, responsável pela regularização ambiental (MINAS GERAIS, 2014).

Entre as atividades regularizadas no Estado, a mineração destaca-se, pois representa $70 \%$ dos processos formalizados com Estudos de Impacto

$\square$

'Universidade Federal de Lavras - Lavras (MG), Brasil.

*Autor correspondente: paula7405@gmail.com

Recebido: 14/02/2017 - Aceito: 29/06/2017 - Reg ABES: 175858 
Ambiental/Relatórios de Impacto Ambiental — EIA/RIMA (MINAS GERAIS, 2014). Excluídos os produtos energéticos, a produção mineral do Estado corresponde a mais de $40 \%$ da fabricação nacional, empregando igual percentual de mão de obra. Há boa variedade de minerais no subsolo, com destaque para minério de ferro, ouro, nióbio e calcário (BRASIL, 2007; VIANA; BURSZTYN, 2010).

As áreas mineradas sofrem ameaças constantes em razão dos interesses econômicos, por isso a autorização do licenciamento ambiental exige uma série de critérios que, se seguidos conforme a legislação, garantem à sociedade e ao ambiente o retorno de uma parte daquilo que está sendo explorado, ou seja, dá-se origem à atividade sustentável. Porém estudos recentes como os de Oliveira et al. (2016) e César \& Carneiro (2017) apontam inúmeras deficiências no processo de avaliação ambiental e de licenciamento ambiental no órgão de controle, demonstrando que a simplificação do processo, a equipe reduzida, a alta burocratização do processo em Minas Gerais, entre outros fatores impedem avanços mais expressivos nos procedimentos.

Assim, este estudo teve como objetivo analisar de forma técnica e legal o licenciamento ambiental minerário na Região do Alto São Francisco, Minas Gerais, por meio do histórico e fluxo atual dos processos, do levantamento de dados dos de Estudos de Impacto Ambiental, cumprimento dos Termos de Referência e legislação ambiental, analisando estes dados por meio da organização hierárquica proposta pelo Centro Internacional para Pesquisa Florestal (CIFOR) e pelo método Analytic Hierarchy Process (AHP).

\section{METODOLOGIA}

O estudo delimitou-se à área de jurisdição da Superintendência Regional de Regularização Ambiental do Alto São Francisco (SUPRAM ASF), que engloba 66 municípios do centro-oeste de Minas Gerais. Foram analisados os estudos de impacto ambiental dos processos de mineração, formalizados entre 2004 e 2013, período definido conforme data de início da regionalização da SEMAD, publicação, em 2004, da Deliberação Normativa COPAM nº 74/2004 (MINAS GERAIS, 2004) e pela representatividade amostral. Excluídos os processos de revalidação de licença de operação, foram utilizados processos de todas as fases de licenciamento com decisão final: deferidos, indeferidos e arquivados. Os processos formalizados com Relatório de Controle Ambiental (RCA) no mesmo período foram avaliados, mas não foram computados nas análises.

Para a avaliação dos dados, foi utilizada a metodologia de Pereira (2011), com base nos critérios do CIFOR. A proposta divide a avaliação de forma hierárquica, em que é necessário o entendimento da condição ideal (princípio) e de como avaliar se os objetos de estudo (critério, indicadores e verificadores) são satisfatórios para alcançá-la. Os dados levantados a partir dos verificadores escolhidos foram avaliados por meio do modelo de métodos de análise hierárquica, proposto por Saaty
(1977; 1990), que busca dar pesos aos itens estudados (verificadores). Assim, os verificadores são arranjados conforme hierarquia previamente estabelecida para obter-se uma matriz de julgamento. A ordem definida no presente estudo foi a seguinte, de acordo com a Quadro 1.

A partir da estrutura hierárquica, foi definida a matriz de julgamento, em que foram atribuídos os valores da escala de comparação entre os verificadores, conforme proposto por Pappa (2012):

- 1: os verificadores contribuem igualmente para o objetivo;

- 3: um verificador contribui ligeiramente em relação ao outro par;

- 5: um verificador é fortemente mais importante que o outro par;

- 7: um verificador é muito mais importante que o outro par;

- 9: um verificador é extremamente mais importante que o outro par;

- 2, 4, 6, 8: valores intermediários, quando é necessário maior compromisso entre julgamentos sucessivos.

Compararam-se os verificadores acima utilizando-se os critérios organizados em uma matriz de julgamento, que teve os pesos convertidos em valores reais (normalizada), sendo que estes exprimem a contribuição de cada parâmetro e alternativa para o alcance do objetivo deste trabalho: quanto o licenciamento ambiental está contribuindo para o desenvolvimento sustentável. Após a normalização da matriz, foram definidos os valores de prioridade média (PM) e os vetores de prioridade. A partir dos resultados desses valores calculou-se o autovalor máximo para, ao final, chegar-se ao índice de consistência. Esses cálculos foram realizados para que a razão de consistência pudesse atingir valor menor que 0,10, pois, segundo Saaty (1990), se a razão for menor que 0,10 , há consistência e coerência para seguir com a metodologia. Se for maior que 0,10 , é recomendado que os julgamentos sejam refeitos até que a consistência aumente.

Utilizando-se os dados encontrados na análise hierárquica foram calculados os valores reais e o percentual de cumprimento de cada verificador e de cada indicador. Para avaliar a contribuição efetiva do licenciamento ambiental para o desenvolvimento sustentável, reconheceremos o valor máximo de cumprimento dos verificadores e dos indicadores, ou seja, $100 \%$. Se todos os verificadores forem cumpridos, quer dizer que o licenciamento ambiental contribui significativamente para o desenvolvimento sustentável.

O peso de cada indicador foi calculado por meio da soma do peso de cada um e a média de cumprimento foi dada pela soma dos percentuais de cumprimento dos indicadores dividida por três, o que resultou no índice de contribuição efetiva (ICE), cujos valores foram agrupados em cinco classes de contribuição.

\section{RESULTADOS E DISCUSSÃO}

Foram analisados 58 e 18 processos com decisão final formalizados, respectivamente, com EIA/RIMA e RCA/PCA. No total, foram 
pesquisados 76 processos, número que está em consonância com os estudos similares mais atuais (HILDEBRANDT; SANDHAM, 2014; JAY et al., 2007; LOBO; PARTIDARIO, 2014; TORO et al., 2014). Em relação à substância mineral requerida, houve destaque para o calcário, substância predominante de 44 processos, ou $57,9 \%$ do total.

Dos 58 processos analisados com EIA/RIMA, 37 foram deferidos, 15, indeferidos e 6, arquivados. Os motivos do indeferimento foram: locacional (1), descumprimento do Termo de Referência (5) e ausência de documentos, anuências ou informações complementares (9). Já dos processos formalizados com RCA/PCA, 11 foram deferidos, 3 , indeferidos e 4, arquivados. O motivo do indeferimento foi o descumprimento do Termo de Referência e o dos arquivamentos, a ausência de informações complementares.
Dos 11 processos que foram formalizados com RCA/PCA, 7 (64\%) deveriam ter sido formalizados com EIA/RIMA, em cumprimento à CF/88 e à Resolução CONAMA nº 1/86 (BRASIL, 1986). A isenção do EIA/RIMA nos casos de mineração se dá somente para as substâncias consideradas Classe II pelo Código de Mineração, que podem ser utilizadas imediatamente na construção civil.

A ausência do EIA/RIMA nesses processos acarreta descumprimento legal, danos ambientais e desequilíbrio da sustentabilidade, pois, no mínimo, deixaram de ser cobradas a compensação financeira do Sistema Nacional de Unidades de Conservação (SNUC) e as compensações florestais. Sem mencionar a ausência do diagnóstico ambiental e a avaliação de impactos que definem a viabilidade locacional e ambiental. De acordo com a Resolução CONAMA nº 1/86 (BRASIL, 1986), somente barragens com potência instalada acima de $10 \mathrm{MW}$

Quadro 1 - Princípio, critérios, indicadores e verificadores em ordem hierárquica.

Princípio: o licenciamento ambiental contribui para o desenvolvimento sustentável

Critério 1:

O licenciamento ambiental contribui para o desenvolvimento

sustentável por meio da elaboração precisa do Estudo e

Relatório de Impacto Ambiental (EIA/RIMA)

1.1 Indicadores

Cumprimento do Termo de Referência (ind. 1)

1.1 Verificadores

Presença de alternativas tecnológicas e locacionais no Estudo de Impacto Ambiental, incluindo a possibilidade de não execução

Identificação e avaliação dos impactos gerados na fase de
implantação e operação do empreendimento (ver. 2)
implantação e operação do empreendimento (ver. 2)

Definição dos limites da área geográfica afetada pelos impactos, denominada área de influência, a partir da bacia hidrográfica (ver. 3)

Presença diagnóstico ambiental da área contendo informações sobre meio físico, biótico e socioeconômico (ver. 4)

Realização de análise dos impactos ambientais, incluindo a previsão da magnitude e interpretação dos impactos relevantes (ver. 5) do projeto (ver. 1)

Critério 2:

O licenciamento ambiental contribui para o desenvolvimento sustentável por intermédio do cumprimento da legislação específica

\subsection{Indicadores}

Pagamento de compensação ambiental e medidas compensatórias florestais (ind. 2)

2.1.1 Verificadores

Pagamento de compensação ambiental conforme Lei Federal no 9.985/00 (ver. 1)

b) Pagamento da medida compensatória conforme Lei

Estadual no 20.922/13 (MINAS GERAIS, 2013) (ver. 2)

Pagamento da medida compensatória conforme Lei Federal 11.428/06 (BRASIL, 2006b) (ver. 3)

Pagamento da medida compensatória conforme DN COPAM 73/2004 (ver. 4)

Pagamento da medida compensatória conforme Resolução CONAMA n0 369/06 (ver. 5)

Identificação das medidas mitigadoras para os impactos negativos, classificando-as quanto à sua natureza; fase em que são adotados; ao fator ambiental ao qual se destinam; ao prazo de permanência de sua aplicação; à avaliação dos custos envolvidos nas medidas mitigadoras e à responsabilidade de implementação (ver. 6)

Elaboração de programas de acompanhamento e monitoramento dos impactos positivos e negativos (ver. 7)

Apresentação do Relatório de Impacto Ambiental (ver. 8)

IBAMA: Instituto Brasileiro do Meio Ambiente e dos Recursos Naturais Renováveis; CONAMA: Conselho Nacional do Meio Ambiente; COPAM: Conselho Estadual de Política Ambiental; IPHAN: Instituto do Patrimônio Histórico e Artístico Nacional; IEPHA: Instituto Estadual do Patrimônio Histórico e Artístico de Minas Gerais.
Apresentação de manifestação prévia dos demais órgãos envolvidos e participação da sociedade (ind. 3)

\subsubsection{Verificadores}

Realização de audiência pública (ver. 1)

b) Apresentação de anuência do IBAMA, conforme Resolução CONAMA 347/2004 ou apresentação de Estudo Relevância conforme Resolução no 2/09 (BRASIL, 2009) (ver. 2)

Apresentação de anuência do IPHAN, conforme IPHAN 01/2015 (ver. 3)

Apresentação de anuência do IEPHA, conforme Lei Estadual no 11.726/1994 e Decreto Estadual 45.850/2014 (ver. 4)

Apresentação de anuência das unidades de conservação conforme Resolução CONAMA no 428/2011 (ver. 5) 
demandariam EIA/RIMA, o que demonstra também que, em muitos casos, a legislação precisa ser revista.

Sobre os sete processos deferidos sem EIA/RIMA, é importante dizer que, além do crivo do órgão licenciador, os processos foram deliberados pelo Conselho Estadual de Política Ambiental. Esse fato demonstra que o processo democrático de votação dos processos de licenciamento ambiental apresenta fragilidades e precisa ser reavaliado constantemente com o intuito de analisar se a sua contribuição ainda é um diferencial ou se a democratização, neste caso, significa burocratização, conforme demonstrado por Carneiro (2003), Zhouri (2008) e Zhouri, Laschefski e Pereira (2005).

Sobre os processos formalizados com EIA/RIMA, de acordo com a matriz hierárquica definida neste trabalho, foi realizado um levantamento do cumprimento dos verificadores nos processos de licenciamento ambiental formalizados com EIA/RIMA, o qual, para o indicador 1, obteve os resultados abaixo discutidos (Figura 1).

Para o indicador 1, todos os verificadores apresentados são itens de cumprimento obrigatório, determinados no Termo de Referência. Eles representam as informações mínimas necessárias para a conclusão da análise de forma satisfatória.

O verificador 1, apresentação de alternativas tecnológicas e locacionais, teve alto índice de não apresentação em decorrência da rigidez locacional da própria atividade; apenas em processos de mineração de ferro houve análise de melhor alternativa tecnológica.

O verificador 3, definição da área afetada, considerou os processos que trouxeram algum tipo de definição da área minimamente afetada; entretanto, dos 44 processos, 23 consideraram a bacia hidrográfica ou a área maior, como no caso da Província Cárstica, para definir a área de influência do empreendimento e 21 processos consideraram a poligonal minerária. Apesar da consideração no cálculo do verificador, justificado pelo fato de que essa informação estava presente de alguma forma, não se deve vincular a área da poligonal minerária à área afetada, pois geralmente a área da poligonal é menor que a área cujos impactos da atividade são sentidos.
Já o verificador 4, diagnóstico ambiental da área, dos 56 processos em que o dado foi apresentado, 29 tiveram o diagnóstico somente com informações secundárias ou com uma campanha de campo. O diagnóstico ambiental é um dos diferenciais do EIA/RIMA em relação aos outros estudos ambientais, visto que ele subsidia a avaliação de impactos e a proposição de medidas mitigadoras e compensatórias de forma assertiva, pois garante que todos os elementos foram considerados. Para a fauna, não existe obrigatoriedade legal da realização das coletas de campo em, no mínimo, duas estações do ano após a alteração da Instrução Normativa IBAMA nº 146/2007 (IBAMA, 2007), que tornava obrigatória, para fins de levantamento, a execução de campanhas que amostrem as espécies, conforme a sazonalidade anual. Esta deve ser considerada somente para empreendimentos hidrelétricos de grande porte.

Em relação ao verificador 5, relacionado à análise dos impactos ambientais, era esperado que, por ser um estudo de maior complexidade, a análise dos impactos no EIA/RIMA deveria também ter um nível de complexidade mais apurado, com análises qualitativas e quantitativas. Contudo, em 28 processos a análise foi realizada por lista simples, em 16 a análise foi realizada por matriz de Leopold e em 11, por lista qualitativa. Essa informação não condiz com os dados apresentados por Oliveira e Moura (2009), que estudaram metodologias de avaliação de impactos no Ceará e encontraram a matriz de Leopold como o principal método. Os demais verificadores estiveram dentro da normalidade esperada, o que não significa que os estudos ambientais foram finalizados satisfatoriamente, uma vez que os itens fundamentais, como diagnóstico, sazonalidade e avaliação de impactos, não obtiveram bons índices de cumprimento, ou a sua análise pormenorizada demonstrou que, qualitativamente, eles não foram bons.

Em relação ao indicador 2, foram obtidos os resultados apresentados na Figura 2.

Para o verificador 1, pagamento de compensação ambiental, prevista na Lei Federal n 9.985/2000 (BRASIL, 2000), todos os processos,

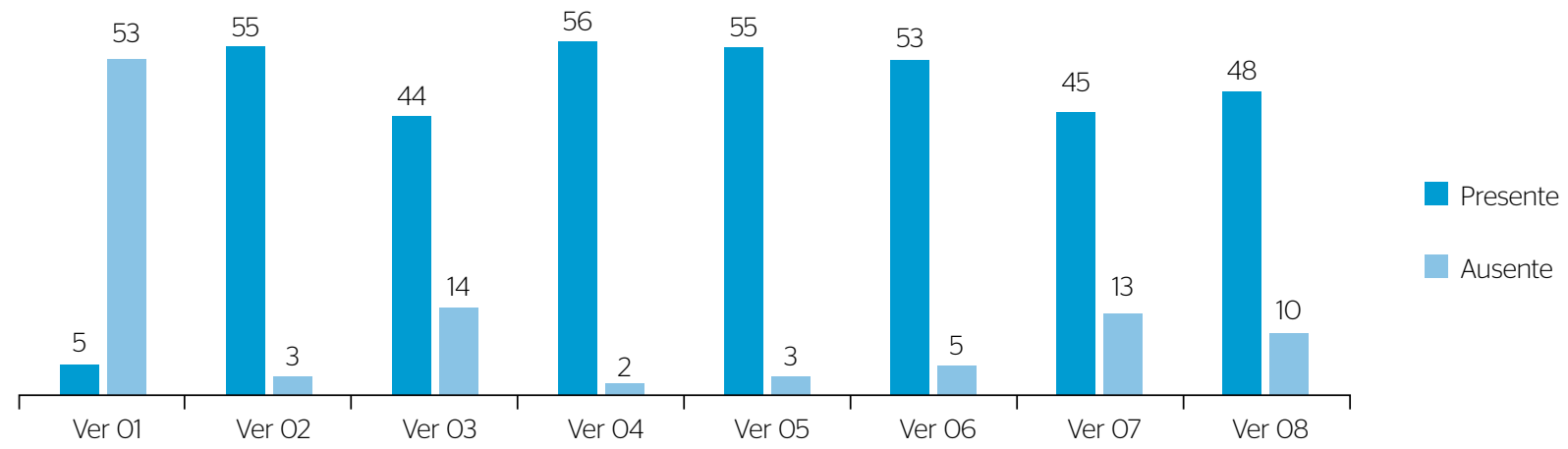

Figura 1 - Ocorrência dos verificadores do indicador 1 em número real de processos. 
obrigatoriamente, deveriam ter a compensação fixada como condicionante obrigatória; entretanto, em 50\% não houve tal cobrança. Não é possível estimar o valor que deixou de ser cobrado e revertido para unidades de conservação. Barros (2013) afirma que a mineração gerou um montante maior que 60 milhões de compensação ambiental, e, apenas em 2012, foi arrecadado 45,7\% do total, correspondendo a quase metade do valor global. A destinação dos recursos da compensação ambiental é muito diversificada, mas a regularização fundiária recebeu $65,6 \%$ dos recursos no mesmo ano.

Recentemente, a Advocacia-Geral do Estado (AGE) definiu, após várias discussões, que a compensação ambiental deveria ser aplicada somente para empreendimentos que iniciaram sua instalação ou operação após a Lei Federal n 9.985/2000 (BRASIL, 2000), incluindo as revalidações de licença. Como vários desses processos foram julgados no período de discussões, a compensação ambiental só será cobrada quando da revalidação da licença. Como o prazo de licença de operação é de até 10 anos, estima-se que até 2023 o passivo ainda será cobrado, sem considerar o prazo de análise do órgão licenciador.

O verificador 2, medida compensatória prevista na Lei Estadual $n^{\circ}$ 20.922/2013 (MINAS GERAIS, 2013) e na revogada Lei Estadual no 14.309/2002 (MINAS GERAIS, 2002), foram consultados 36 processos, cuja compensação estava presente ou não se aplicava. Nos casos em que ela não se aplicava foi considerada presente, tendo em vista que a ausência não representou perda ambiental ou social. Esses casos foram os processos de licenças indeferidas ou arquivadas em que não houve lavra, portanto, não houve a efetivação do impacto.

Em 22 processos, as licenças foram concedidas sem a condicionante ou as licenças foram indeferidas ou arquivadas sem a cobrança da compensação, mesmo havendo lavra pretérita, assim, o cumprimento da medida seria obrigatório. Entre os processos em que a área impactada pela atividade de mineração estava identificada, foi possível levantar o déficit de 341 ha.
Os verificadores 3 e 4, referentes à fixação da medida compensatória, determinada pela Lei Federal no 11.428/2006 (BRASIL, 2006b) e a sua proporção de 2:1, respectivamente, tiveram índice razoável de cumprimento. Foram considerados como presentes as medidas compensatórias em processos em que a lei não se aplicava por não haver prejuízo ambiental ou social.

Dos processos em que houve supressão de fitofisionomia de mata Atlântica ou que a supressão se deu dentro dos limites do bioma, em seis deles a compensação foi cobrada na proporção de 1:1, ou seja, a cada 1 ha suprimido, 1 ha foi protegido ou recuperado. $O$ não atendimento à proporção prevista na Deliberação Normativa COPAM $\mathrm{n}^{\circ}$ 73/06 acarretou um déficit de 68,5 ha. Todas as fitofisionomias de Mata Atlântica e todas aquelas dentro do bioma são protegidas; assim, o respeito a essa proporcionalidade garante, ao final do cálculo, que tenhamos mais áreas protegidas e recuperadas do que aquelas que foram impactadas.

O verificador 5 demonstrou um número não significativo em termos amostrais, pois a medida compensatória, prevista na Resolução CONAMA n 369/06 (BRASIL, 2006a), referente à recuperação das áreas de preservação permanente, deixou de ser cobrada em apenas quatro processos, contudo não foi possível levantar a extensão dessas áreas.

Para o verificador 6, demarcação da reserva legal, 24 processos foram finalizados sem a verificação da demarcação da área de reserva legal. Esperava-se que esse número fosse menor, uma vez que, de todos os verificadores, este é o que tem temática mais comum e disseminada e sua instituição é a mais antiga de todos os verificadores, datada de 1934.

Em relação ao cumprimento dos verificadores do indicador 3, a Figura 3 representa os principais resultados.

Os verificadores do indicador 3 tiveram a pior taxa de cumprimento. A participação popular na decisão do processo de licenciamento apresentou-se baixa, ao ponto de ser insignificante nos processos amostrados, conforme verificador 1 . Em apenas três processos a audiência pública foi realizada; destes, dois foram indeferidos, mas

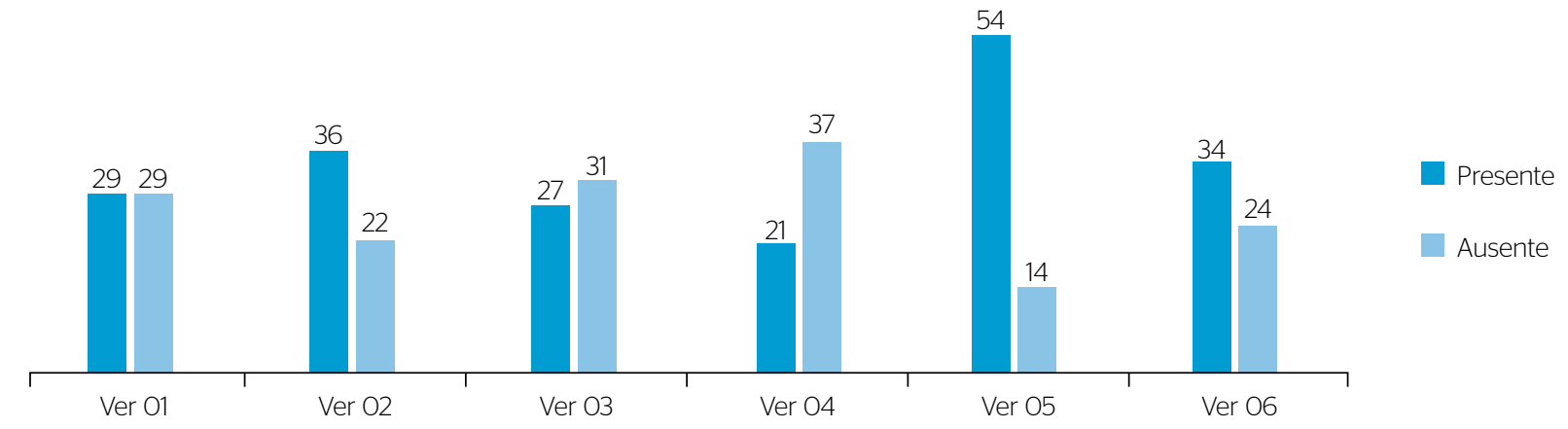

Figura 2 - Ocorrência dos verificadores do indicador 2 em número real de processos. 
não em decorrência da realização da audiência, e sim pela ausência da entrega de informações complementares pelo empreendedor. Pode-se dizer que processo de licenciamento ambiental em Minas Gerais não é simples para os principais envolvidos, como consultores, empreendedores, órgão ambiental e conselho de política ambiental, quiçá para a sociedade.

Entre as dificuldades que podem ser apontadas, estão a publicitação do processo, que se dá por meio do Diário Oficial de Minas Gerais e pelos jornais de circulação regional ou local, meios pouco utilizados pela população; o fato de os processos não estarem disponíveis para consulta em sua integralidade; além de os RIMAs serem resumos do EIA, o que não facilita seu entendimento, bem como a apresentação demasiadamente técnica do estudo durante as audiências públicas. Há de se ressaltar que a população só tem interesse pelos estudos quando é afetada diretamente pelo projeto. Por fim, a avaliação de viabilidade locacional e ambiental é realizada pelo empreendedor antes da formalização da Licença Prévia e a audiência pública ocorre durante a tramitação do processo no órgão licenciador, ou seja, ela chega ao órgão predefinida.

O verificador 2, referente à anuência do Instituto Brasileiro do Meio Ambiente e dos Recursos Naturais Renováveis (IBAMA) ou à apresentação de Estudo de Relevância, conforme a Instrução Normativa do Ministério do Meio Ambiente n 2/2009 (BRASIL, 2009), apresentou índice baixo de presença nos processos de licenciamento, presente em apenas 16 deles, sendo que 13 mostraram anuência do IBAMA e 3 apresentaram o Estudo de Relevância.

Apesar de o item espeleologia ser constante nos processos de licenciamento, ele geralmente foi visto nos processos como composição dos itens do diagnóstico ambiental, e não como item à parte. Analisando tal dado no cenário da regional, em que se pese a análise da Província Cárstica, a situação é bem crítica, pois 42 processos foram finalizados sem informações precisas da existência de cavidades naturais e se estas têm espécies de fauna e flora endêmicas, raras ou ameaçadas, muito comuns nessas regiões.
Segundo a Sociedade Brasileira de Espeleologia (2015), por meio de registros do Cadastro Nacional de Cavernas, existem 1.923 cavernas cadastradas em Minas Gerais, tendo a Província Cárstica 474 cadastrados nesta base. Já o Projeto Arcos Pains Espeleologia (PROAPE, 2012) menciona o número de 753 cavidades existentes nessa região.

$\mathrm{O}$ verificador 3, referente à anuência do Instituto do Patrimônio Histórico e Artístico Nacional (IPHAN), teve índice de cumprimento baixo, em que apenas 12 processos com decisão final apresentaram anuência da instituição para obtenção da licença ambiental. Nos outros 46 processos foi possível identificar a apresentação de um diagnóstico arqueológico, mas cada qual com sua metodologia.

$\mathrm{O}$ verificador 4, referente à anuência do Instituto Estadual do Patrimônio Histórico e Artístico de Minas Gerais (IEPHA), foi o que apresentou o pior índice de cumprimento, pois em nenhum dos processos finalizados entre 2004 e 2013 houve manifestação da instituição. Como a finalidade do IEPHA é pesquisar, proteger e promover o patrimônio cultural em Minas Gerais, é possível concluir que nenhum estudo considerou esse impacto como significativo, ouvindo a quem lhe é de direito.

Entretanto, somente em 2014, com a publicação do Decreto Estadual $n^{\circ} 45.850$, que estabelece o Estatuto do IEPHA, as funções desse órgão ficaram mais claras aos stakeholders do licenciamento, inclusive o Conselho Estadual de Patrimônio Cultural, que editou, em dezembro de 2014, a Deliberação CONEP n 07/2014, que estabelece normas para realização do estudo de impacto no patrimônio cultural em Minas Gerais.

Por fim, o verificador 5 cumpriu significativamente o seu índice de presença nos licenciamentos, pois apenas quatro processos deixaram de apresentar a anuência das unidades de conservação, localizadas na sua área de influência.

\section{Análise hierárquica dos dados}

A partir da definição dos verificadores foi criada a matriz de julgamento, onde foram atribuídos valores a cada verificador comparado a

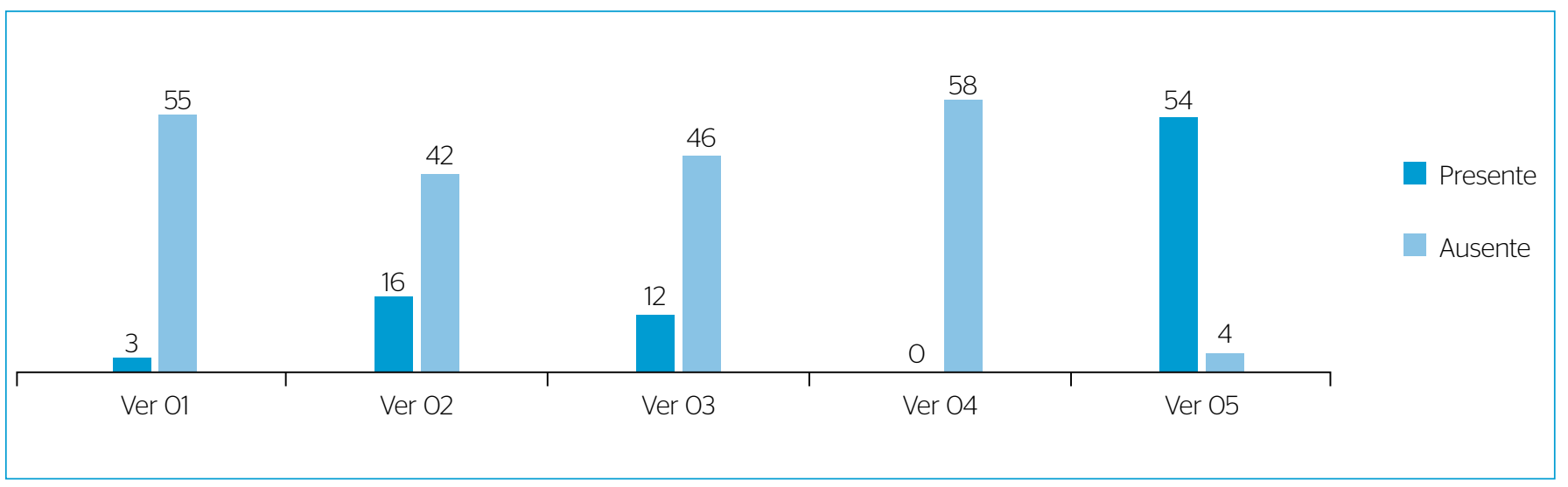

Figura 3 - Ocorrência dos verificadores do indicador 3 em número real de processos. 
seu par. Posteriormente, a matriz de julgamento foi normalizada (matriz normalizada), onde os números foram convertidos em números reais. Este procedimento foi realizado para cada indicador separadamente. Após a normalização das matrizes foram calculados os valores de PM, que demonstram o valor do verificador com os demais elementos da coluna. Daí foram calculados os vetores de prioridade para se chegar ao autovetor máximo, que por sua vez participou do cálculo do Índice de Consistência. Este índice é a demonstração da consistência de uma matriz positiva recíproca. $\mathrm{O}$ autovalor máximo deveria ser igual a $\mathrm{n}$ (dimensão da matriz). No caso de uma matriz consistente será preciso n-1 comparações paritárias já que, a partir destas, as outras foram deduzidas logicamente. Os valores correspondentes ao autovalor máximo e ao Índice de Consistência dos Indicadores podem ser visualizados abaixo:

- Ind. 1: autovalor máximo: 9,161 e índice consistência do indicador: 0,166 ;

- Ind. 2: autovalor máximo: 6,555 e índice consistência do indicador: 0,111;

- Ind. 3: autovalor máximo: 5,288 e índice consistência do indicador: 0,072;

A razão de consistência define a coerência nos julgamentos. Para calculá-la, são utilizados o índice de consistência e o índice randonômico, este último obtido em laboratório e já previamente definido por Saaty (1977):

- $\mathrm{RC}=$ índice de consistência/índice randonômico
- $\quad \mathrm{RC}$ indicador $1=0,166 / 1,41-\mathrm{RC}$ indicador $1=0,11$

- $\mathrm{RC}$ indicador $2=0,111 / 1,24-\mathrm{RC}$ indicador $2=0,09$

- $\mathrm{RC}$ indicador $3=0,072 / 1,12-\mathrm{RC}$ indicador $3=0.06$

Os indicadores podem ser definidos como o somatório dos valores (somatório dos itens verificadores) reais da PM, mas, para chegar a esse valor, é necessário calcular o percentual de cumprimento de cada verificador multiplicado pelo peso encontrado para cada um, de acordo com a Tabela 1.

Após a verificação do percentual de cumprimento de cada verificador, foi calculado o percentual de cumprimento de cada indicador com a Equação 1, em que PC indicador = soma dos percentuais de cumprimento dos verificadores $/ \mathrm{n}^{\circ}$ de verificadores.

PC indicador $1=77,80 \%$ PC indicador $2=57,13 \%$ PC indicador $3=24,34 \%$

Para avaliar a contribuição efetiva do licenciamento ambiental para o desenvolvimento sustentável, reconhece-se o valor máximo de cumprimento dos verificadores, ou seja, $100 \%$. O cálculo cumprimento de cada indicador é dado pelo percentual de cumprimento de cada indicador multiplicado pelo peso de cada um.

O percentual de cumprimento foi calculado pela soma dos percentuais de cumprimento de cada verificador dividido pelo número de verificadores. O peso de cada indicador foi calculado pela soma do peso de cada indicador. Encontrado o peso de cada um, a média

Tabela 1 - Cálculo do percentual de cumprimento de cada verificador.

\begin{tabular}{|c|c|c|c|c|c|}
\hline \multicolumn{2}{|c|}{ Indicador 1} & \multicolumn{2}{|c|}{ Indicador 2} & \multicolumn{2}{|c|}{ Indicador 3} \\
\hline & Valor & & Valor & & Valor \\
\hline $\begin{array}{l}\text { Verificador } 1 \\
(8,62 \times 0,393)\end{array}$ & 3,39 & $\begin{array}{l}\text { Verificador } 1 \\
(50 \times 0,453)\end{array}$ & 22,65 & $\begin{array}{l}\text { Verificador } 1 \\
(5,17 \times 0,498)\end{array}$ & 2,57 \\
\hline $\begin{array}{l}\text { Verificador } 2 \\
(94,83 \times 0,192)\end{array}$ & 18,21 & $\begin{array}{l}\text { Verificador } 2 \\
(58,33 \times 0,205)\end{array}$ & 11,96 & $\begin{array}{l}\text { Verificador } 2 \\
(2,76 \times 0,214)\end{array}$ & 0,59 \\
\hline $\begin{array}{l}\text { Verificador } 3 \\
(75,86 \times 0,127)\end{array}$ & 9,63 & $\begin{array}{l}\text { Verificador } 3 \\
(46,55 \times 0,130)\end{array}$ & 6,05 & $\begin{array}{l}\text { Verificador } 3 \\
(20,69 \times 0,133)\end{array}$ & 2,75 \\
\hline $\begin{array}{l}\text { Verificador } 4 \\
(96,55 \times 0,094)\end{array}$ & 9,08 & $\begin{array}{l}\text { Verificador } 4 \\
(36,21 \times 0,069)\end{array}$ & 2,50 & $\begin{array}{l}\text { Verificador } 4 \\
(\mathrm{O} \times 0,070)\end{array}$ & $\mathrm{O}$ \\
\hline $\begin{array}{l}\text { Verificador } 5 \\
(94,83 \times 0,051)\end{array}$ & 4,84 & $\begin{array}{l}\text { Verificador } 5 \\
(93,10 \times 0,052)\end{array}$ & 4,84 & $\begin{array}{l}\text { Verificador } 5 \\
(93,10 \times 0,043)\end{array}$ & 4 \\
\hline $\begin{array}{l}\text { Verificador } 6 \\
(91,38 \times 0,041)\end{array}$ & 3,75 & $\begin{array}{l}\text { Verificador } 6 \\
(58,62 \times 0,033)\end{array}$ & 1,93 & & \\
\hline $\begin{array}{l}\text { Verificador } 7 \\
(77,59 \times 0,027)\end{array}$ & 2,09 & & & & \\
\hline \multirow[t]{2}{*}{$\begin{array}{l}\text { Verificador } 8 \\
(82,76 \times 0,023)\end{array}$} & 1,90 & & & & \\
\hline & 52,89 & & 49,93 & & 9,91 \\
\hline Total indicador 1 & 0,948 & Total indicador 2 & 0,942 & Total indicador 3 & 0,958 \\
\hline
\end{tabular}


de cumprimento foi dada por meio de soma dos percentuais de cumprimento dos indicadores dividida por três. Foram obtidos os seguintes resultados:

$\mathrm{ICE}=73,75+53,81+23,31 / 3=50,25 \%$

Os valores assumidos pelo ICE, avaliado mediante a aplicação das equações supracitadas, foram agrupados em cinco classes de contribuição, conforme cumprimento:

- Muito baixa: 0 a $20 \%$;

- Baixa: 21 a $40 \%$;

- Média: 41 a $60 \%$; ICE $=50,25 \%$

- Alta: 61 a $80 \%$;

- Muito alta: 81 a $100 \%$

Desse modo, com base na pesquisa realizada, é possível afirmar que os processos de mineração analisados e finalizados na jurisdição da Superintendência Regional de Meio Ambiente (SUPRAM) Alto São Francisco têm contribuição média para o alcance do desenvolvimento sustentável da região. $\mathrm{O}$ indicador que contribuiu negativamente foi o indicador 3 , referente à manifestação dos órgãos envolvidos, principalmente o verificador 4, relativo à anuência do IEPHA. O verificador 3 , referente à anuência do IPHAN, também contribuiu negativamente.

$\mathrm{O}$ indicador 1 apresentou o maior percentual de cumprimento, entretanto, cada verificador poderia se desdobrar em outros tantos, caso cada item (fatores ambientais) do Termo de Referência fosse analisado separadamente. É relevante destacar que, mesmo não sendo objeto deste estudo, chamou a atenção o fato de os processos com classes mais elevadas (Classes 5 e 6) pela Deliberação Normativa COPAM n 74/04 (MINAS GERAIS, 2004) apresentarem estudos mais completos que os processos de empreendimentos das Classes 3 e 4 . Nos processos da Província Cárstica, cuja atividade principal é a extração do calcário, houve predomínio de uma empresa de consultoria ambiental, e o diagnóstico ambiental foi o mesmo, em todos os estudos de impacto ambiental.

O indicador 2 apresentou percentual de cumprimento mediano, mas é o item de maior retorno para a sociedade e para o ambiente, sendo o item que apresentou déficit nas medidas compensatórias. E, considerando que os recursos da compensação são destinados a fonte única de arrecadação do Estado, e não somente ao Sistema Estadual do Meio Ambiente (SISEMA), essa situação se potencializa, pois os valores arrecadados não retornam para aplicação imediata.

Foi possível avaliar que, mesmo que o ICE apresente um número cujo percentual representa contribuição média, há desproporção na conta ambiental desses projetos, pois há uma parcela maior recebida pelo setor produtivo, ou seja, para os empreendedores, e uma parcela bem menor sendo recebida pelo ambiente e pela sociedade, o que contradiz o viés do desenvolvimento sustentável.
Trabalhos anteriores demonstram a situação semelhante dos estudos ambientais e do próprio licenciamento de forma disseminada em todo o país (PRADO FILHO; SOUZA, 2004; ZHOURI, 2008; FEARNSIDE, 2011; FEARNSIDE; LAURENCE, 2012; JERONYMO; BERMANN; GUERRA, 2012)

Há um efeito guarda-chuva no modelo atual de licenciamento ambiental, que foge da esfera estudada e avaliada pelo EIA/RIMA, por vezes pela má qualidade dos estudos, por vezes pela distorção da participação popular no processo de decisório, o que culmina em imputações aos empreendedores, em casos em que a responsabilidade seria do poder público, fazendo com que o licenciamento ambiental, principal instrumento da PNMA, que deveria ser um documento de cunho científico, torne-se um fenômeno sociopolítico que envolve dimensões ou domínios ecológico, social, político e econômico (TAMBELLINI, 2012).

\section{CONCLUSÃO}

De acordo com os resultados apresentados, é possível afirmar que a mineração na Região do Alto São Francisco não se desenvolve de forma sustentável, uma vez que o ICE representou pouco mais de 50\% de cumprimento dos verificadores analisados. Este trabalho demonstra que o licenciamento ambiental não atende a nenhuma das partes de forma satisfatória. Pelo órgão ambiental, há sobrecarga de processos, falta de valorização dos servidores, falta de equipamentos e sistemas adequados para o trabalho, rotatividade constante de profissionais. Pelos empreendedores, há delonga na emissão de resposta acerca do pedido, demasiados envolvidos diretamente no processo, pedidos fragmentados de informações complementares e falta de comunicação entre os envolvidos. Pelo ambiente, há déficit ambiental significativo por conta da ausência de cobrança e da consolidação das devidas compensações, bem como das atividades poluidoras executadas sem fiscalização.

Entre os instrumentos da PNMA, o licenciamento ambiental impera quase isolado, enquanto outros instrumentos tão necessários ao desenvolvimento sustentável são preteridos do processo, como a avaliação de impactos ambientais, o zoneamento ambiental, os incentivos econômicos, especialmente o pagamento por serviços ambientais, entre outros. Ferramentas essas que poderiam trazer celeridade e segurança ao processo e deixar para trás a falácia do desenvolvimento sustentável.

Por fim, vale destacar que é importante discutir novas alternativas, sem extinguir o modelo participativo que é a marca do licenciamento em Minas Gerais, pois o licenciamento ambiental demonstrou pouca evolução da sua implementação até os dias atuais, requerendo maior atenção de todos os envolvidos, mas principalmente de ferramentas de análise integrada, análise de paisagem e programas avançados de geoprocessamento, para finalizar com a metodologia cartorial difundida nesse modelo. 


\section{REFERÊNCIAS}

BARROS, E.C. (2013) Estudo da compensação ambiental aplicada ao Estado de Minas Gerais. 117f. Dissertação (Mestrado em Engenharia Florestal) - Universidade Federal de Lavras, Lavras.

BRASIL. (1981) Lei Federal no 6.938, de 31 de agosto de 1981. Dispõe sobre a Política Nacional do Meio Ambiente, seus fins e mecanismos de formulação e aplicação, e dá outras providências. Brasília. Disponível em: <http://www.planalto.gov.br>. Acesso em: 10 nov. 2014.

(1986) Resolução CONAMA no 1, de 17 de fevereiro de 1986. Dispõe sobre critérios básicos e diretrizes gerais para o Relatório de Impacto Ambiental-RIMA. Brasília. Disponível em: <http://www. planalto.gov.br>. Acesso em: 5 maio 2014.

(2000) Lei Federal no 9.985, de 18 de julho de 2000. Regulamenta o art. 225, § 10, incisos I, II, III e VII da Constituição Federal, institui o Sistema Nacional de Unidades de Conservação da Natureza e dá outras providências. Brasília. Disponível em: <http://www.planalto.gov.br/ccivil_O3/leis/L9985.htm>. Acesso em: 6 abr. 2016.

(2006a) Conselho Nacional do Meio Ambiente. Lei no 369, de 28 de março de 2006. Dispõe sobre os casos excepcionais, de utilidade pública, interesse social ou baixo impacto ambiental, que possibilitam a intervenção ou supressão de vegetação em Área de Preservação Permanente-APP. Brasília. Disponível em: <http://www. mma.gov.br/port/conama/legiabre.cfm?codlegi=489>. Acesso em: 7 abr. 2016

(2006b) Lei Federal no 11.428, de 22 de dezembro de 2006. Dispõe sobre a utilização e proteção da vegetação nativa do bioma mata Atlântica, e dá outras providências. Brasília. Disponível em: <http://www.planalto.gov.br/ccivil_03/_ato2004-2006/2006/ lei//11428.htm>. Acesso em: 5 jun. 2016

(2007) Departamento Nacional de Produção Mineral. Universo da mineração brasileira. Brasília: DNPM. 83 p.

(2009) Ministério de Meio Ambiente. Instrução Normativa $\overline{n^{\circ}} 2$ de 16 de agosto de 2009. Classificação de cavernas. Brasília. Disponível em: <http://www.icmbio.gov.br/cecav/images/ download/IN\%2002_MMA_criterios_210809.pdf>. Acesso em: 5 maio 2014.

CABRAL, E.R. (2006) Institucionalização da questão ambiental e exploração mineral no Pará e Minas Gerais: valorização da natureza e inversão da imagem da mineração? Revista de la Red Iberoamericana de Economía Ecológica, Morelia, v. 5, p. 27-45.

CARNEIRO, E.J. (2003) Modernização recuperadora e o campo da política ambiental em Minas Gerais. 449f. Tese (Doutorado em Sociologia e Política) - Universidade Federal de Minas Gerais, Belo Horizonte.

CÉSAR, P.S.M.; CARNEIRO, R. (2017) A gestão ambiental em Minas Gerais: uma análise do sistema de gestão ambiental e do rompimento da barragem de rejeitos em Mariana. Revista Livre de Sustentabilidade e Empreendedorismo, Paraná, v. 2, n. 2, p. 192-217.
FEARNSIDE, P.M. (2011) Gases de efeito estufa no EIA/RIMA da hidrelétrica de Belo Monte. Novos Cadernos NAEA, Belém, v. 14 n. 1, p. 5-19. http://dx.doi.org/10.5801/ncn.v14i1.596

FEARNSIDE, P.M.; LAURENCE, W.F. (2012) Infraestrutura na Amazônia: as lições dos planos plurianuais. Caderno CRH, Salvador, v. 25, n. 64, p. 87-98. http://dx.doi.org/10.9771/ccrh.v25i64.19333

HILDEBRANDT, L.; SANDHAM, L.A. (2014) Social impact assessment: the lesser sibling in the South African. Environmental Impact Assessment Review, Nova York, n. 48, p. 20-26.

INSTITUTO BRASILEIRO DO MEIO AMBIENTE E DOS RECURSOS NATURAIS RENOVÁVEIS (IBAMA). Instrução normativa no 146, de 11 de janeiro de 2007. Brasília: IBAMA. 10 p.

JAY, S.; JONES, C.; SLINN, P.; WOOD, C. (2007) Environmental impact assessment: retrospect and prospect. Environmental Impact Assessment, Nova York, v. 27, n. 4, p. 287-300. https://doi. org/10.1016/j.eiar.2006.12.001

JERONYMO, A.C.J.; BERMANN, C.; GUERRA, S.M.G. (2012) Considerations about the deconstruction of Brazilian environmental licensing. Raega, Curitiba, v. 26, p. 182-204.

LOBO, V: PARTIDARIO, M. (2014) Theory versus practice in Strategic Environmental Assessment (SEA). Environmental Impact Assessment Review,Nova York, n.48, p.34-46. http://dx.doi.org/10.1016/j.eiar.2014.04.004

MINAS GERAIS. (1980) Lei Estadual no 7.772, de 8 de setembro de 1980. Dispõe sobre a proteção, conservação e melhoria do meio ambiente. Belo Horizonte. Disponível em: <http://www.siam. mg.gov.br>. Acesso em: 6 maio 2014.

(2002) Lei Estadual no 14.309 de 19 de junho de 2002. Dispõe sobre as políticas florestal e de proteção à biodiversidade no estado. Belo Horizonte. Disponível em: <http://www.almg.gov.br/ consulte/legislacao/completa/completa.html?tipo=LEl\&num=1430 9\&ano=2002>. Acesso em 5 maio 2015.

(2004) Conselho Estadual de Política Ambiental - COPAM no 74/2004. Estabelece critérios para classificação, segundo o porte e potencial poluidor, de empreendimentos e atividades modificadoras do meio ambiente passiveis de autorização ambiental de funcionamento ou de licenciamento ambiental no nível estadual, determina normas para indenização dos custos de análise de pedidos de autorização ambiental e de licenciamento ambiental, e dá outras providencias. Diário do Executivo, Belo Horizonte. 112 p.

(2013) Lei Estadual no 20.922, de 16 de outubro de 2013. Dispõe sobre as Políticas Florestal e de Proteção à Biodiversidade no Estado de Minas Gerais. Belo Horizonte. Disponível em: <http:// www.almg.gov.br>. Acesso em: 10 mar. 2015.

. (2014) Deliberação Normativa no 007, de 3 de dezembro de 2014. Estabelece diretrizes para a realização do EIPC e RIPC no Estado de Minas Gerais. Belo Horizonte. Disponível em: <http:// www.cultura.mg.gov.br>. Acesso em: 5 maio 2014. 
OLIVEIRA, F.C.; MOURA, H.JT. (2009) Uso das metodologias de avaliação de impacto ambiental em estudos realizados no Ceará. Pretexto, Belo Horizonte, v. 10, n. 4, p. 79-98. http://dx.doi.org/10.21714/pretexto.v10i4.498

OLIVEIRA, F.S.D.; PRADO FILHO, J.F.; ROCHA, C.F.; FONSECA, A. (2O16) Licenciamento ambiental simplificado na região sudeste brasileira: conceitos, procedimentos e implicações. Desenvolvimento e Meio Ambiente, Paraná, v. 38, p. 461-479. http://dx.doi.org/10.5380/dma. v38i0.42297

PAPPA, M.F. (2012) Aplicação da metodologia AHP na hierarquização dos critérios de qualidade do trânsito das cidades. 100f. Dissertação (Mestrado em Engenharia Civil) - Universidade Estadual de Maringá, Maringá.

PEREIRA, G.M. (2011) Proposta de procedimento para avaliação de autossustentabilidade em projetos de restauração florestal. 100f. Dissertação (Mestrado em Ciências Florestais) - Universidade Federal de Lavras, Lavras.

PRADO FILHO, J.F.; SOUZA, M.P. (2004) O licenciamento ambiental da mineração no Quadrilátero Ferrífero de Minas Gerais: uma análise da implementação de medidas de controle ambiental formuladas em EIAs/RIMAs. Engenharia Sanitária e Ambiental, Rio de Janeiro, v. 9, n. 4, p. 343-349. http://dx.doi.org/10.1590/S1413-41522004000400012

Projeto ARCOS PAINS ESPELEOLOGIA (PROAPE). (2012) Área cárstica de Pains. Ouro Preto: Sociedade Excursionista Espeleológica, Departamento de Geologia da Escola de Minas da Universidade Federal de Ouro Preto, UFMG. 550 p.

RELATÓRIO DE BRUNDTLAND: our common future. (1987) Oxford: Oxford University Press.

RONZA, C. (1998) A política de meio ambiente e as contradições do estado: a avaliação de impactos ambientais em São Paulo. 108f. Dissertação (Mestrado em Política Científica e Tecnológica) Universidade Estadual de Campinas, Campinas.
SAATY, T.L. (1977) A scaling method for priorities in hierarchical structures. Journal of Mathematical Psychology, Nova York, v. 15, n. 3, p. 234-281. https://doi.org/10.1016/00222496(77)90033-5

(1990) Decision making for leaders: the analytic hierarchy process for decisions in a complex world. 2. ed. Pittsburgh: University of Pittsburgh. 323 p.

Sociedade Brasileira de Espeleologia. Cadastro nacional de cavernas do Brasil. Disponível em: <http://www.sbe.com.br>. Acesso em: 25 abr. 2015.

TAMBELLINI, A.T. (2012) Sobre o licenciamento ambiental no Brasil, país potência emergente. Ciência \& Saúde Coletiva, Rio de Janeiro, v. 17, n. 6, p. 1399-1406. http://dx.doi.org/101590/S141381232012000600003

TORO, J.; REQUENA, I.; DUARTE, O.; ZAMORANO, M. (2014) A qualitative method to improve environmental impact assessment. Environmental Impact Assessment Review, Nova York, v. 43, p. 9-20. https://doi.org/10.1016/j.eiar.2013.04.004

VIANA, M.B.; BURSZTYN, A.A.A. (2010) Regularização ambiental de minerações em Minas Gerais. Revista Escola de Minas, Ouro Preto, v. 63, n. 2, p. 363-369. http://dx.doi.org/10.1590/S037044672010000200022

ZHOURI, A. (2008) Justiça ambiental, diversidade cultural e accountability: desafios para a governança ambiental. Revista Brasileira de Ciências Sociais, São Paulo, v. 23, n. 68, p. 97-107. http:// dx.doi.org/10.1590/S0102-69092008000300007

ZHOURI, A.; LASCHEFSKI, K.; PEREIRA, D. (2005) A insustentável leveza da política ambiental: desenvolvimento e conflitos socioambientais. Belo Horizonte: Autêntica. 288 p. 